\title{
COVID-19 crisis monitor: assessing the effectiveness of exit strategies in the State of São Paulo, Brazil
}

\author{
Eduardo A. Haddad ${ }^{1,2}$ - Renato S. Vieira ${ }^{3}$ (D) Inácio F. Araújo ${ }^{1}$ (D) \\ Silvio M. Ichihara ${ }^{4} \cdot$ Fernando S. Perobelli $^{5}$ (D) Karina S. S. Bugarin $^{6}$
}

Received: 23 February 2021 / Accepted: 12 October 2021 / Published online: 23 November 2021

(c) The Author(s), under exclusive licence to Springer-Verlag GmbH Germany, part of Springer Nature 2021

\begin{abstract}
As COVID-19-related health indicators improve after restrictive measures were set in place in different parts of the world, governments are expected to guide how to ease interventions while minimizing the risk of resurgent outbreaks. Whereas epidemiologists track the progress of the disease using daily indicators to understand the pandemic better, economic activity indicators are usually available at a lower frequency and with considerable time lags. We propose and implement a timely trade-based regional economic activity indicator (EAI) that uses high-frequency traffic data to monitor daily sectoral economic activity in different sectors for the Brazilian State of São Paulo, a highly impacted region, overcoming the challenge of real-time assessment of the economy amid the COVID-19 outbreak. We then use this novel set of information combined with hospitalization rates to provide a first assessment of the São Paulo Plan, the COVID-19 exit strategy designed to gradually lifting interventions introduced to control the outbreak in the State. Available data show that, in its first 60 days, the phased strategy pursued in São Paulo has been effective in gradually reactivating economic activity while maintaining the adequate responsiveness of the healthcare system.
\end{abstract}

JEL Classification C55 $\cdot$ C67 $\cdot$ R11 $\cdot$ R40

\section{Introduction}

The COVID-19 pandemic has brought unforeseen and unpredictable effects in terms of both health and economics. With unprecedented research efforts that generated several articles tackling clinical presentation, preventive and treatment measures, and possible correlated and permanent effects of the disease, as well as various other articles exploring its economic effects (from micro to macroeconomic elements),

Eduardo A. Haddad

ehaddad@usp.br

Extended author information available on the last page of the article 
researchers worldwide seek to contribute with actionable insight to tackle the challenges presented by the pandemic.

The State of São Paulo, a highly impacted, densely populated area that represents the economic core of Brazil, sought to follow in the footsteps of Asian, European, and other countries in the use of evidence to design policy intervention (OECD 2020; European Commission 2020; World Health Organization 2020; Oxford Martin School-Global Health Platform 2020; Haddad and Bugarin 2020). To better understand the evolution of the disease and its territorial economic impacts due to social distancing measures, the State government established a set of parameters to manage the crisis. This endeavor was tackled alongside a network of researchers and qualified public sector personnel and ultimately led to the institutionalization of two consulting bodies - one composed of health professionals (Contingency Centre) and another of economists (Economic Council)—-to advise on necessary policy to mitigate the sanitary and economic effects of the disease.

Once the data and indicators used to monitor the disease were defined and officially announced, a new challenge arose: guaranteeing effective monitoring of economic indicators. The central argument is the need to pave the way for sound cost-benefit analysis between more flexible economic operations and the spread of the disease. The effectiveness of sanitary safeguard measures is bounded by the economic stress on households due to reduced income as a side product of guaranteeing health service attendance. With the São Paulo Plan, ${ }^{1}$ economic activities started slowly taking up operations after a period of closure and suspension. However, there may be an imminent threat of disease spread with increased economic activity, which still needed to be quantified.

There is vast literature relating the demand for freight and passenger transport to economic activity (Boyce and Williams 2015). A usual question in project appraisal is whether one can predict the evolution of domestic demand for freight [and passenger] transport to a reasonably high level of explanation with a few readily available variables (Bennathan et al. 1992). As transport is a derived demand, its activity level, in general, relates to the output levels in an economy. Therefore, one of the critical elements in forecasting traffic demand models is the information on economic trends. Studies often find a close link between GDP and traffic levels, which becomes more evident when the elements making up the GDP forecasts are identified (Cole 2005; Ortúzar and Willumsen 2011).

More recently, a related strand of research has benefitted from the availability of detailed traffic-flow data based on sensor readings to reverse the question and look at ways of using traffic intensity metrics ${ }^{2}$ to construct coincident and leading indicators of regional economic activity (van Ruth 2014; Hooijmaaijers 2017; Nolan 2019; Li et al. 2020). However, weights based on traffic flows measured taking into account only direct links involving the study region neglect the intricate structure of

\footnotetext{
${ }^{1}$ For a detailed description of the São Paulo Plan, please refer to https://www.saopaulo.sp.gov.br/plano $\mathrm{sp} /$, information in Portuguese.

${ }^{2}$ As Garcia et al. (2008) observed, whereas it is fairly accepted that freight transport, measured in ton$\mathrm{km}$, is closely related to the level of economic activity of a region, there is hardly any study that investigates if this correlation still holds for transport indicators that are independent of the volumes transported.
} 
interregional input-output flows that may affect regional activity. Combining traffic intensity data in the whole network with measures of regional economic activity embedded in trade relations everywhere may enhance the accuracy of the indicator by accounting for the systemic nature of a region's output (Sonis et al. 1996).

There are alternatives to the use of high-frequency data on sensor readings to address this issue. The Transportation Services Index (TSI), for instance, created by the US Department of Transportation (DOT), Bureau of Transportation Statistics (BTS), measures the monthly movement of freight and passengers, combining available data on freight traffic, as well as passenger travel (Lahiri et al. 2002). The monthly measurement of transportation services output at the national level has proved important to follow business cycles in the USA (Lahiri and Yao 2011). Nonetheless, its relatively low frequency, the time lag in its release, and aggregate geographical dimension impose limitations to its use as an indicator for timely monitoring of regional economic activity.

We add to this debate departing from a similar approach to van Ruth (2014), who has shown that it is possible to construct indicators of regional economic activity based on local traffic intensity data. In her monthly indicator of traffic intensity in the Eindhoven region, in the Netherlands, she convincingly showed the link between traffic intensity and economic activity at the regional level. However, the choice of the study region was based on its high specialization in manufacturing activities, justifying the procedure of computing daily averages over all sensors in the sample. Accordingly, such a procedure defined for a broader range of areas presenting different degrees of economic specialization could lead to a less clear correlation.

Therefore, we propose a novel indicator of regional economic activity that tackles some of the issues mentioned above. A good index should be simple, policy-relevant, reliable, and timely (National Research Council 2002). We rely on close-toreal-time big data sources (i.e., radar sensors) and structural economic statistics (i.e., input-output system), which represent useful economic concepts to create a set of indicators that allow early identification of significant economic changes. In doing that, we provide insight into economic activity, at a level of timeliness and granularity not possible for official economic statistics, achieving the desired goals pursued in modern economic activity monitoring projects (Nolan 2019). We then show the usefulness of the proposed indicator for policy evaluation in the context of a regionally heterogeneous plan designed to mitigate the economic effects of the COVID-19 pandemic in São Paulo, Brazil. ${ }^{3}$

This article presents a novel approach to complementary crisis monitoring strategies. A link between high-frequency transportation flows (cargo and passengers) and sanitary results, through economic indicators, may shed light on possible future disease outbreaks and pave the way to a cost-benefit analysis. Section 2 lays out the mathematical model behind the empirical strategy for specifying and implementing

\footnotetext{
3 The Treasury Department in São Paulo tracks overall economic activity in the State monitoring daily value-added tax (VAT) collection and VAT-generating transactions. In spite of its usefulness, this indicator has a partial coverage of the state economy, as the VAT tax base is restricted to approximately onethird of GRP, including mainly manufacturing activities in the formal sector, with a poor coverage of services activities. Moreover, it does not provide a regional disaggregation yet.
} 
Table 1 Regional value-added in trade flows, by sector

\begin{tabular}{|c|c|c|c|c|c|c|}
\hline \multirow[t]{2}{*}{ Origin } & \multicolumn{6}{|c|}{ Destination } \\
\hline & $\mathrm{R}_{1}$ & $\mathrm{R}_{2}$ & $\cdots$ & $\mathrm{R}_{n-1}$ & $\mathrm{R}_{n}$ & ROW \\
\hline $\mathrm{R}_{1}$ & $v a_{1,1}^{r, s}$ & $v a_{1,2}^{r, s}$ & $\cdots$ & $v a_{1, n-1}^{r, s}$ & $v a_{1, n}^{r, s}$ & $v a_{1, \text { row }}^{r, s}$ \\
\hline $\mathrm{R}_{2}$ & $v a_{2,1}^{r, s}$ & $v a_{2,2}^{r, s}$ & $\cdots$ & $v a_{2, n-1}^{r, s}$ & $v a_{2, n}^{r, s}$ & $v a_{2, \text { row }}^{r, s}$ \\
\hline$\vdots$ & $\vdots$ & $\vdots$ & & $\vdots$ & $\vdots$ & $\vdots$ \\
\hline $\mathrm{R}_{n-1}$ & $v a_{n-1,1}^{r, s}$ & $v a_{n-1,2}^{r, s}$ & $\cdots$ & $v a_{n-1, n-1}^{r, s}$ & $v a_{n-1, n}^{r, s}$ & $v a_{n-1, r o w}^{r, s}$ \\
\hline $\mathrm{R}_{n}$ & $v a_{n, 1}^{r, s}$ & $v a_{n, 2}^{r, s}$ & $\cdots$ & $v a_{n, n-1}^{r, s}$ & $v a_{n, n}^{r, s}$ & $v a_{n, r o w}^{r, s}$ \\
\hline ROW & $v a_{r o w, 1}^{r, s}$ & $v a_{r o w, 2}^{r, s}$ & $\cdots$ & $v a_{r o w, n-1}^{r, s}$ & $v a_{n, n}^{r, s}$ & $v a_{\text {row,row }}^{r, s}$ \\
\hline
\end{tabular}

our novel regional sectoral economic activity index and presents its results. The index combines input-output analysis and traffic data. As an example of potential applications of the proposed index, Sect. 3 then addresses the link between economic activity and the spread of COVID-19 in the context of the São Paulo Plan. The empirical results highlight the link between transportation flows within and between regions, economic activity disaggregated by tradable and non-tradable sectors, and the spread of the disease, providing the first systematic assessment of the Plan. The analysis reveals that the phased strategy pursued in São Paulo has been effective in reactivating economic activity while maintaining the adequate responsiveness of the healthcare system. Finally, we discuss applying the results in guiding policy design and possible implications for COVID-19 exit strategies pursued elsewhere.

\section{Monitoring regional sectoral economic activity}

\subsection{Methodology}

The purpose of this section is to present the general structure of the proposed index of regional economic activity that considers each region's insertion into an integrated multi-sectoral interregional system. We consider there are $n$ domestic regions, $r=1, \ldots, \mathrm{n}$, and the rest of the world, row, which exhaust the space of the economy. Economic interactions take place inside and outside each region (intraregional, interregional, and international trade). In our multi-sectoral economy, there are $j$ sectors, $s=1, \ldots, \mathrm{j}$, provided by $n+1$ different sources.

We then assume we can measure, for each sector $s$ in region $r$, the value-added contents embedded in trade flows associated with each regional origin-destination pair, such that we can complete the information in Table 1.

According to Table 1, a region's sectoral output is potentially associated with transactions involving economic agents located in the region and elsewhere. Define the sets of origins, $O$, and destinations, $D$, both comprising all domestic regions, $r$, and add the rest of the world, row. Thus, we can compute the total value-added of sector $s$ in region $r, v a^{r s}$, as 


$$
v a^{r s}=\sum_{o \in O, d \in D} v a_{o, d}^{r, s}
$$

We also calculate the region's $r$ total value-added, $v a^{r}$, as

$$
v a^{r}=\sum_{s} v a^{r s}
$$

In order to monitor sectoral, regional economic activity, we would need to follow $v a^{r s}$ over time. This information, when available, is usually published with a delay and at a low frequency (annual). To circumvent such informational constraints, we could track changes in trade flows for each regional origin-destination pair and combine them with the information in Table 1 to calculate a trade-weighted index of regional economic activity.

Thus, if we can observe, in each period $t$, changes in values of flows from each origin $o$, to each destination $d, \Delta F_{t, o, d}$, a regional index of economic activity could be calculated as

$$
E A I_{t}^{r, s}=\sum_{o \in O, d \in D} w_{o, d}^{r, s} \Delta F_{t, o, d}
$$

where $E A I_{t}^{r, s}$ is the economic activity index for sector $s$, in region $r$, in time $t$, and the weights $w_{o, d}^{r, s}$ are calculated as

$$
w_{o, d}^{r, s}=\frac{v a_{o, d}^{r, s}}{\sum_{o \in O, d \in D} v a_{o, d}^{r, s}}
$$

such that

$$
\sum_{o \in O, d \in D} w_{o, d}^{r, s}=1
$$

The implementation of the index depends on two pieces of information: first, we need to define an empirical strategy to estimate values in Table 1 so that we can define the weights, $w_{o, d}^{r, s}$; second, we have to collect timely information to estimate $\Delta F_{t, o, d}$. In what follows, we describe our empirical approach to this problem.

\subsection{Measurement of domestic value-added in trade flows}

This sub-section reports on the results of an application with an interregional input-output matrix for Brazil, ${ }^{4}$ which allows calculating the total value-added that is embodied in specific trade flows. This set of information generates estimates for Table 1. Thus, the concept of embedded value-added in this paper is defined within

\footnotetext{
4 This section draws on Haddad et al. (2020).
} 
the input-output framework, which determines the value-added content via coefficients of sectoral value-added per monetary unit of a given sector. ${ }^{5}$ The input-output system was developed as part of a technical cooperation initiative involving researchers from the Regional and Urban Economics Lab at the University of São Paulo (NEREUS), the Institute of Economic Research Foundation (FIPE), and the State of São Paulo Secretariat of Economic Development (FIPE-NEREUS 2020). A fully specified interregional input-output database was estimated for 2015, considering 67 sectors in 17 regions (Regional Health Departments) in the State of São Paulo, and a residual endogenous domestic region, the rest of Brazil. We estimate, for each flow originated in one of the Brazilian regions, measures of value-added in trade that are further used to calculate our index. The parsimonious approach proposed in Los et al. (2016), based on "hypothetical extraction," serves as the methodological anchor.

The input-output model can be expressed by

$$
\begin{gathered}
\mathbf{x}=\mathbf{A} \mathbf{x}+\mathbf{f} \\
\mathbf{x}=(\mathbf{I}-\mathbf{A})^{-1} \mathbf{f}=\mathbf{L f}
\end{gathered}
$$

where $\mathbf{x}$ and $\mathbf{f}$ are the vectors of gross output and final demand; $\mathbf{A}$ is a matrix with the input coefficients $\left(a_{i j}\right)$; $\mathbf{I}$ is the identity matrix; and $\mathbf{L}$ is the Leontief inverse.

Considering a national interregional input-output model with $n$ different regions and the ROW as a column vector in the final demand, (6) and (7) can be represented as $^{6}$

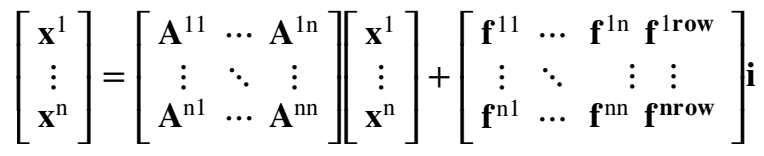

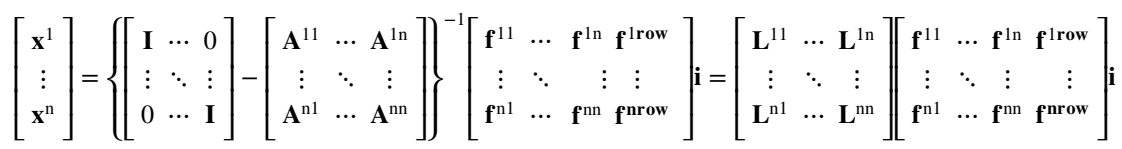

where $\mathbf{i}$ is a column vector with all elements equal unity, which sums all elements in each of the $n+1$ rows of the matrix $\mathbf{f}$.

Following Los et al. (2016), the value-added in region $r\left(v a^{r}\right)$ can be expressed as

\footnotetext{
5 Regional value-added in our input-output database varies by sector and region, reflecting different dimensions of agglomeration economies (e.g., Henderson, 1986; Mum and Hutchison, 1995; Beenstock et al., 2011). For instance, in the two largest metropolitan areas, Grande São Paulo and Campinas, which present a large share of their value-added in manufacturing and services sectors, the average value-added per worker was equivalent to BRL 80,074 and BRL 89,472, respectively. On the other hand, the average value-added per worker in more agricultural, peripheral regions, such as Registro and Presidente Prudente, reached BRL 47,667 and BRL 51,450, respectively (see also Table 3 for a comparison between regional population size and GDP per capita).

6 In this application, the rest of the world is an endogenous region, which precludes the possibility of including the effects of foreign sales on a domestic region's performance.
} 


$$
v a^{1}=\mathbf{v}_{1}(\mathbf{I}-\mathbf{A})^{-1} \mathbf{f i}
$$

where $\mathbf{v}_{1}$ is a row vector with ratios of value-added to gross output in the $j$ sectors in region $n$ as elements $\left(\tilde{\mathbf{v}}_{1}\right)$ and zeros elsewhere $\left(\mathbf{v}_{1}=\left[\begin{array}{ll}\tilde{\mathbf{v}}_{1} & 0\end{array}\right]\right)$; and $\mathbf{i}$ is a column vector in which all elements are unity.

In order to attribute the amount of domestic value-added in sales from region 1 to domestic region $n$, as proposed by Los et al. (2016), we consider a hypothetical world where region 1 does not sell anything to region $n$. In this case, the new valueadded or hypothetical value-added can be represented by

$$
v a_{1, n}^{*}=\mathbf{v}_{1}\left(\mathbf{I}-\mathbf{A}_{1, n}^{*}\right)^{-1} \mathbf{f}_{1, n}^{*} \mathbf{i}
$$

where $\mathbf{A}_{1, n}^{*}$ and $\mathbf{f}_{1, n}^{*}$ are the hypothetical matrix of input coefficients and final demand, respectively, expressed as

$$
\begin{gathered}
\mathbf{A}_{r, t}^{*}=\left[\begin{array}{ccc}
\mathbf{A}^{11} & \cdots & 0 \\
\vdots & \ddots & \vdots \\
\mathbf{A}^{\mathrm{n} 1} & \cdots & \mathbf{A}^{\mathrm{nn}}
\end{array}\right] \\
\mathbf{f}_{1, n}^{*}=\left[\begin{array}{cccc}
\mathbf{f}^{11} & \cdots & 0 & \mathbf{f}^{1 \text { row }} \\
\vdots & \ddots & \vdots & \vdots \\
\mathbf{f}^{\mathrm{n} 1} & \cdots & \mathbf{f}^{\text {nn }} & \mathbf{f}^{\text {nrow }}
\end{array}\right]
\end{gathered}
$$

In addition, to attribute the amount of domestic value-added in exports from region $l$ to the row, we consider a hypothetical world where region 1 does not export to the row. In this case, the hypothetical value-added can be represented as

$$
v a_{1, \text { row }}^{*}=\mathbf{v}_{1}(\mathbf{I}-\mathbf{A})^{-1} \mathbf{f}_{1, \text { row }}^{*} \mathbf{i}
$$

where $\mathbf{A}$ is the original matrix with the input coefficients as in (10); and $\mathbf{f}_{1, \text { row }}^{*}$ is the hypothetical matrix of final demand, expressed as

$$
\mathbf{f}_{1, \text { row }}^{*}=\left[\begin{array}{cccc}
\mathbf{f}^{11} & \cdots & \mathbf{f}^{1 \mathrm{n}} & 0 \\
\vdots & \ddots & \vdots & \vdots \\
\mathbf{f}^{\mathrm{n} 1} & \cdots & \mathbf{f}^{\mathrm{nn}} & \mathbf{f}^{\text {nrow }}
\end{array}\right]
$$

From (10) and (11), we can define the regional value-added (across all sectors) in sales from region 1 to region $n$ as follows: ${ }^{7}$

$$
v a_{1, n}^{1, \bullet}=v a^{1}-v a_{1, n}^{*}
$$

\footnotetext{
7 Similar measures can be calculated for each sector $s$ in region $1, v a_{1, n}^{1, s}$.
} 
Table 2 Domestic value-added in trade flows in an interregional system with exogenous ROW, by sector

\begin{tabular}{lllllll}
\hline $\begin{array}{l}\text { Hypo- } \\
\text { thetical no } \\
\text { export }\end{array}$ & To & & & & & \\
From & $\mathrm{R}_{1}$ & $\mathrm{R}_{2}$ & $\cdots$ & $\mathrm{R}_{n-1}$ & $\mathrm{R}_{n}$ & $\mathrm{ROW}$ \\
\hline $\mathrm{R}_{1}$ & $v a_{1,1}^{r, s}$ & $v a_{1,2}^{r, s}$ & $\ldots$ & $v a_{1, n-1}^{r, s}$ & $v a_{1, n}^{r, s}$ & $v a_{1, \text { row }}^{r, s}$ \\
$\mathrm{R}_{2}$ & $v a_{2,1}^{r, s}$ & $v a_{2,2}^{r, s}$ & $\ldots$ & $v a_{2, n-1}^{r, s}$ & $v a_{2, n}^{r, s}$ & $v a_{2, \text { row }}^{r, s}$ \\
$\vdots$ & $\vdots$ & $\vdots$ & & $\vdots$ & $\vdots$ & $\vdots$ \\
$\mathrm{R}_{n-1}$ & $v a_{n-1,1}^{r, s}$ & $v a_{n-1,2}^{r, s}$ & $\ldots$ & $v a_{n-1, n-1}^{r, s}$ & $v a_{n-1, n}^{r, s}$ & $v a_{n-1, r o w}^{r, s}$ \\
$\mathrm{R}_{n}$ & $v a_{n, 1}^{r, s}$ & $v a_{n, 2}^{r, s}$ & $\cdots$ & $v a_{n, n-1}^{r, s}$ & $v a_{n, n}^{r, s}$ & $v a_{n, \text { row }}^{r, s}$ \\
\hline & & & & & &
\end{tabular}

and, from (10) and (14), we can define regional value-added (across all sectors) from region 1 to the ROW as

$$
v a_{1, \text { row }}^{1, \bullet}=v a^{1}-v a_{1, \text { row }}^{*}
$$

Similarly, we can attribute the regional value-added in transactions from region $l$ to all regions $(1,2, \ldots, n)$, and from each region to the $n$-regions $(1,2, \ldots, n)$, including itself. We can also attribute the regional value-added from each region to the ROW. In this sense, in an interregional system with $n$ regions and the ROW exogenous, we can compute regional value-added embedded in trade flows for the $n$ domestic regions, as illustrated in Table 2.

\subsection{Use of traffic intensity indicators as a measure of change in trade volumes}

This sub-section describes how we calculate changes in traffic volumes during the pandemic using high-frequency traffic data from different sources in the State of São Paulo, including automated vehicle identification on toll stations and smart-camera records. These datasets allow us to track specific vehicles and infer their origin and destination in each trip that they make. We then aggregate these trips in order to calculate the total traffic flows of passenger and freight (light commercial vehicles and trucks) vehicles between all pairs of regions (Regional Health Departments) in each day of our analyses. The overall procedure consists of seven steps, which we detail next.

1. First, we extract data from automated vehicle identification from 341 toll stations located on inter-municipal highways in the State of São Paulo. In the year 2018, 600 million registers were collected in these toll stations. Each register includes a vehicle identifier, a toll station identifier, and a timestamp. Therefore, we can identify the exact moment when each vehicle crossed each toll station and calculate the trip duration between any two records. We can define the trip route by connecting consecutive records from the same vehicle, considering four 
parameters to join the legs: time between toll passages, inversion direction angle, accumulated distance, and rest time for truck drivers.

2. This dataset from toll stations is then combined with similar information from 4870 smart cameras located in urban areas of the state. These cameras recorded 3 billion vehicle registers during the year 2018. By combining both datasets, we can expand the temporospatial coverage of our tracking and be more precise about trip segments made within urban areas.

3. We aggregate and anonymize individual trips to guarantee travelers' privacy based on the combined dataset of records from toll stations and smart cameras. Next, a gravitational distribution model, considering the fleet of cars and trucks as an attraction factor per zone, is used to estimate origins and destinations of aggregated trips by day and by pair of origin and destination. Given the spatial coverage of tolls and smart cameras, we can aggregate flows using 1,054 traffic zones in the state, including one zone for every 645 municipalities, 24 frontier zones, and 385 additional subdivisions to split larger cities and transportation hubs.

4. The origin and destination flows calculated in the previous step are then allocated to a highway simulation network and calibrated with expansion weights to match the average daily volume of vehicles from several other sources by the Transport Department of São Paulo.

5. The calibrated highway simulation network is a powerful tool to provide any transport engineering analysis, but it is static when considering the average flows of a year. Therefore, traffic variations from 451 monitoring stations (toll plazas, Service Level—LOS, fixed radar speed system) are used to update the highway simulation network and its matrices of passenger and freight vehicles.

6. The updated information is made available to decision-makers through an online Business Intelligence Dashboard System. The information extracted from these dashboards is the aggregated traffic flows by day and by pair of regions both by passenger and freight vehicles. This level of aggregation is the same one used in our integrated framework of interregional trade flows as described in the previous section.

7. For tracking the traffic flow development during the pandemic, each dataset is updated within the monitoring system according to its technological limitations. For example, data from toll stations are updated every six hours, and data from monitoring equipment of LOS were updated every three days.

\subsection{Descriptive results}

Based on Eq. (3), the EAI was calculated from March 29 to August 1, 2020. ${ }^{8}$ For each day, the index was also calculated for each of the 17 Regional Health Departments (DRS in Portuguese) and two groupings of sectors (tradable and non-tradable)

\footnotetext{
${ }^{8}$ Data were processed on July 3, 2020. There were weekly releases of the daily indicators throughout the pandemic period.
} 
Table 3 Number of Municipalities, GDP, and Population: State of São Paulo, by DRS-region (2017.) Source: Instituto Brasileiro de Geografia e Estatística (IBGE): "Produto Interno Bruto dos Municípios"—https://sidra.ibge.gov.br/tabela/5938, and "População residente estimada"—https://sidra. ibge.gov.br/tabela/6579

\begin{tabular}{|c|c|c|c|c|}
\hline Region & Municipalities & GDP (Billion BRL) & $\begin{array}{l}\text { Population } \\
\text { (Million) }\end{array}$ & $\begin{array}{l}\text { GDP Per } \\
\text { Capita (1000 } \\
\text { BRL) }\end{array}$ \\
\hline DRS I—Grande São Paulo & 39 & 1140.6 & 21.4 & 53.3 \\
\hline DRS II-Araçatuba & 40 & 23.3 & 0.8 & 29.9 \\
\hline DRS III-Araraquara & 24 & 37.0 & 1.0 & 36.7 \\
\hline DRS IV_-Baixada Santista & 9 & 61.1 & 1.8 & 33.4 \\
\hline DRS V-Barretos & 18 & 17.6 & 0.4 & 40.2 \\
\hline DRS VI-Bauru & 68 & 56.1 & 1.8 & 31.7 \\
\hline DRS VII_Campinas & 42 & 287.3 & 4.5 & 63.3 \\
\hline DRS VIII-Franca & 22 & 22.6 & 0.7 & 32.0 \\
\hline DRS IX_Marília & 62 & 34.0 & 1.1 & 29.9 \\
\hline DRS X-Piracicaba & 26 & 68.4 & 1.6 & 44.0 \\
\hline DRS XI-Presidente Prudente & 45 & 21.9 & 0.8 & 28.4 \\
\hline DRS XII-Registro & 15 & 8.5 & 0.3 & 29.9 \\
\hline DRS XIII-Ribeirão Preto & 26 & 60.1 & 1.5 & 40.5 \\
\hline DRS XIV—São João da Boa Vista & 20 & 27.4 & 0.8 & 33.1 \\
\hline DRS XV—São José do Rio Preto & 102 & 51.9 & 1.6 & 32.4 \\
\hline DRS XVI—Sorocaba & 48 & 91.9 & 2.5 & 37.1 \\
\hline DRS XVII-Taubaté & 39 & 110.3 & 2.5 & 44.2 \\
\hline State of São Paulo & 645 & 2119.9 & 45.1 & 47.0 \\
\hline$\%$ of Brazil & 11.6 & 32.2 & 21.7 & 148.3 \\
\hline
\end{tabular}

and the State total. ${ }^{9}$ Changes in values of flows from each origin $o$ to each destination $d, \Delta F_{t, o, d}$, reflect rolling-seven-day averages to take into account weekly seasonality.

The choice of DRS to define the regional setting is particularly relevant for the COVID-19 crisis monitoring in the State of São Paulo. Each DRS is responsible, among other things, for investment planning, monitoring and advertising of health analyses and indicators, epidemiological and risk analysis, and control of the application of state and federal resources allocated to the health system. The use of a common regionalization also provides a cognitive alignment between health scientists and economists on the analysis of regional processes. Table 3 presents basic socioeconomic indicators for the $17 \mathrm{DRS}$ in the state. It is noteworthy the relevance

\footnotetext{
${ }^{9}$ Out of the 67 economic activities defined in the interregional input-output table, we aggregated all 38 agricultural and manufacturing activities into the tradable sector, and all 29 services activities into the non-tradable sector. We used the information on traffic flows of passengers between all pairs of regions together with the latter, while using freight vehicles with the former.
} 


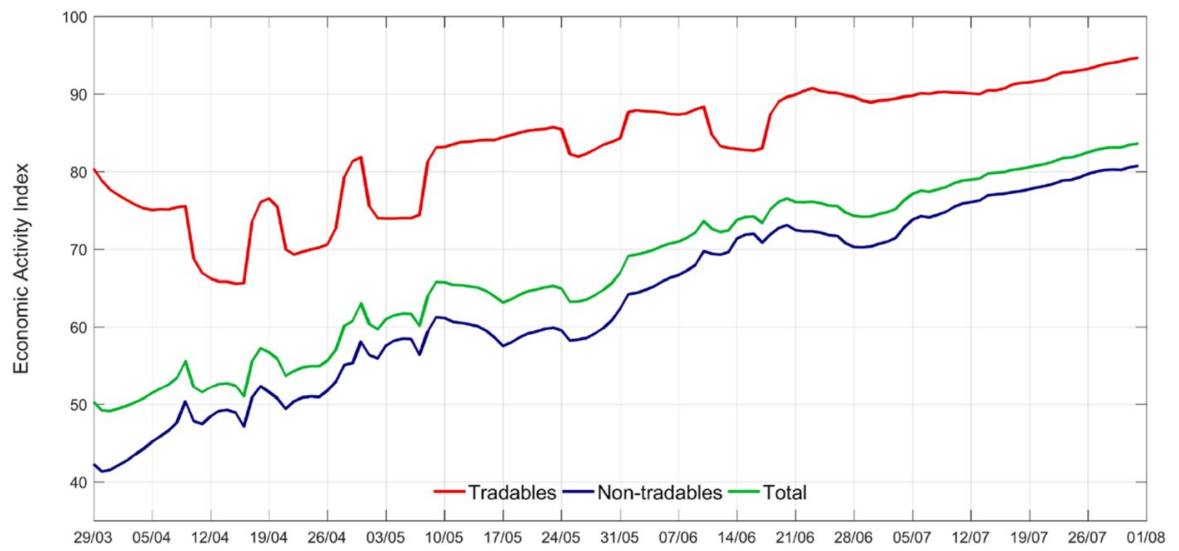

Fig. 1 Economic Activity Index: State of São Paulo (March 29-August 1, 2020)

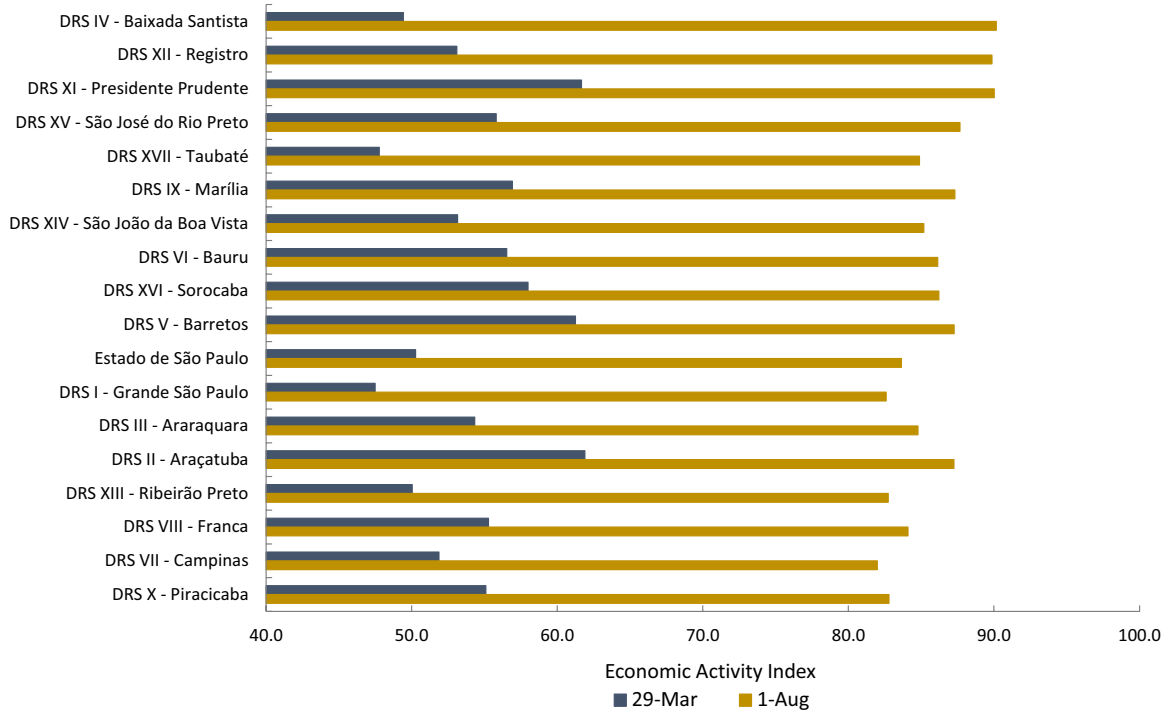

Fig. 2 Economic Activity Index, by DRS (March 29 and August 1, 2020)

of the São Paulo Metropolitan Region, associated with DRS I, that hosts $47.4 \%$ of the state population and is responsible for $53.8 \%$ of its GDP.

The average value for the total EAI was $50.27 \%$ on March 29, indicating that, on average, economic activity in São Paulo was 49.73 percentage points below 
29 - August 1, 2020)

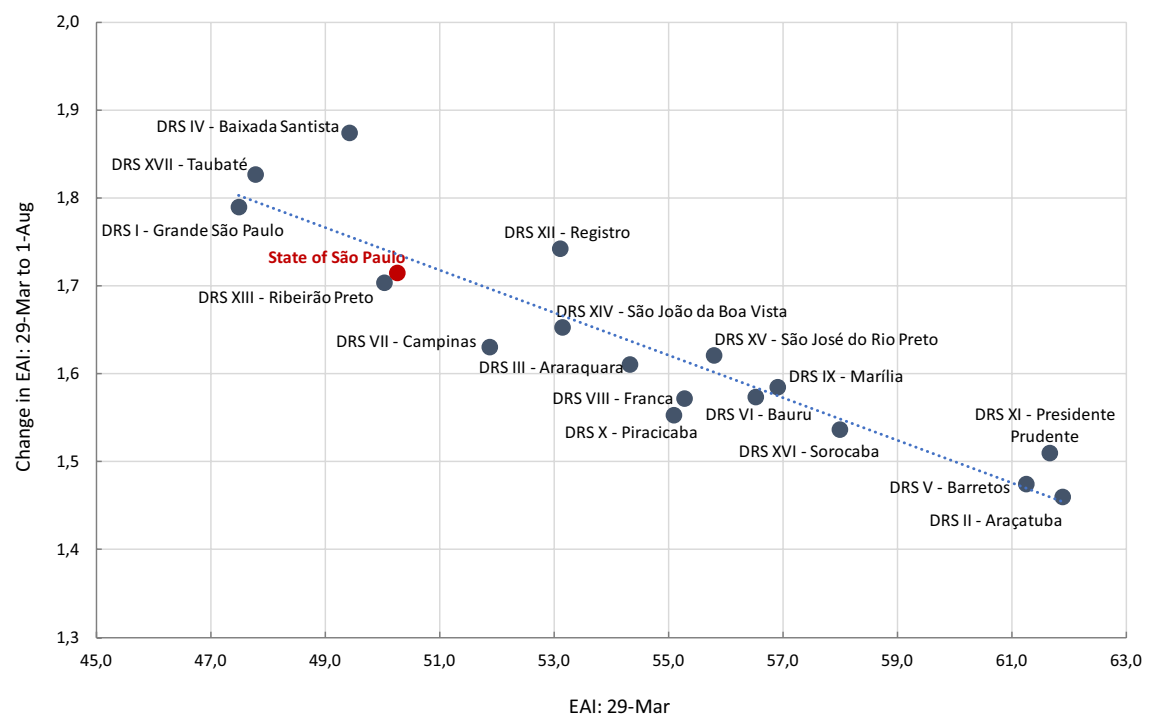

Fig. 3 Regional Convergence of the Economic Activity Index, by DRS (March 29_August 1, 2020)

the pre-crisis level. ${ }^{10}$ At the end of the period (August 1), the State economy had already recovered 33.21 percentage points, presenting an EAI equal to $83.48 \%$. Figure 1 plots the average EAI for the State by different sectors. ${ }^{11}$ Economic activities faced different degrees of exposition to confinement measures after the initial shutting down of non-essential businesses in March. Non-tradable sectors (i.e., services) were the most affected, presenting an EAI equal to $42.33 \%$ (57.67 p.p. below the pre-crisis level), while tradable sectors seemed economically less vulnerable the pandemic as the EAI reached $80.44 \%$ on March 29.

Sectors and regions were affected in different ways, with the main urbanized areas facing more substantial restrictions. Figure 2 shows the average EAI within each of the DRS, presenting different levels of economic vulnerability at the beginning of the pandemic. Initial economic losses were more heavily concentrated in the regions that most contribute to the state's GRP, which coincide with the most densely populated areas. As we will see in the next section, more densely populated regions are also the main vector for promoting contamination amid the initial outbreak of coronavirus in São Paulo. The recovery rate was neither homogenous across regions. In Fig. 2, DRS are ranked from top to bottom according to the recovery speed, measured as the ratio of change in the EAI in the period and the initial distance from the pre-crisis level. Part of the difference is associated with the regionally differentiated

\footnotetext{
10 The EAI measures economic activity in relation to the average of the first three weeks of March 2020, considered as the benchmark pre-crisis level.

11 Appendix presents similar plots within each DRS.
} 
Table 4 Coronavirus Cases: State of São Paulo, by DRS (accumulated until August 1, 2020). Source "Boletins informativos e casos do coronavírus por município por dia." Available: https://brasil.io/dataset/ covid19/caso_full/. Original source: State Health Departments

\begin{tabular}{|c|c|c|c|c|}
\hline \multirow[t]{2}{*}{ Region } & \multicolumn{2}{|c|}{ Confirmed cases } & \multicolumn{2}{|l|}{ Deaths } \\
\hline & Value & $\%$ & Value & $\%$ \\
\hline DRS I—Grande São Paulo & 306,945 & 55.6 & 15,680 & 67.5 \\
\hline DRS II-Araçatuba & 7468 & 1.4 & 201 & 0.9 \\
\hline DRS III-Araraquara & 5904 & 1.1 & 97 & 0.4 \\
\hline DRS IV_Baixada Santista & 36,420 & 6.6 & 1376 & 5.9 \\
\hline DRS V—Barretos & 4311 & 0.8 & 140 & 0.6 \\
\hline DRS VI—Bauru & 15,224 & 2.8 & 321 & 1.4 \\
\hline DRS VII—Campinas & 54,204 & 9.8 & 1884 & 8.1 \\
\hline DRS VIII—Franca & 3264 & 0.6 & 86 & 0.4 \\
\hline DRS IX—Marília & 5267 & 1.0 & 127 & 0.5 \\
\hline DRS X-Piracicaba & 19,581 & 3.5 & 570 & 2.5 \\
\hline DRS XI—Presidente Prudente & 4186 & 0.8 & 133 & 0.6 \\
\hline DRS XII-Registro & 3496 & 0.6 & 72 & 0.3 \\
\hline DRS XIII—Ribeirão Preto & 18,657 & 3.4 & 612 & 2.6 \\
\hline DRS XIV—São João da Boa Vista & 5266 & 1.0 & 143 & 0.6 \\
\hline DRS XV—São José do Rio Preto & 22,923 & 4.2 & 615 & 2.6 \\
\hline DRS XVI—Sorocaba & 21,660 & 3.9 & 644 & 2.8 \\
\hline DRS XVII-Taubaté & 17,420 & 3.2 & 535 & 2.3 \\
\hline State of São Paulo & 552,318 & 100.0 & 23,236 & 100.0 \\
\hline$\%$ of Brazil & 20.4 & & 24.8 & \\
\hline
\end{tabular}

flexibility measures contemplated in the São Paulo Plan, as we will make it more evident in the next section.

While the analysis of Fig. 2 reveals different levels of regional resilience based on a conditional convergence framework, we can also look at the evolution of the EAI in each region, comparing its initial level to its growth rate in the period. Figure 3 presents an apparent process of absolute convergence in the regional EAI, i.e., regional economies that have been hardest hit by the COVID-19 pandemic outbreak are those that presented the fastest recovery.

\section{Economic activity and the spread of COVID-19}

The relation between the uneven geography of the pandemic within countries and local economic activity has gained interest since the beginning of the outbreak. Pioneering studies relied on large-scale structural modeling to run ex-ante assessments based on simulations to look at short-term regional economic impacts of control strategies for mitigating the effects of coronavirus (Bonet et al. 2020; Capello and 
Caragliu 2021; Haddad et al. 2021). As the pandemic progressed and more information became available, other authors started looking at ex-post relationships between the sub-national geography of the COVID-19 pandemic spread and (i) urban density (Hamidi et al. 2020), (ii) the economic base of local economies (Ascani et al. 2021), (iii) local institutions (Rodríguez-Pose and Burkina 2021), or (iv) regional connectivity (Bourdin et al. 2021).

Some attempts to elucidate the effects of different levels of economic activity on the spread of coronavirus in the context of exit strategies relied more commonly on applying different specifications of the susceptible/exposed/infective/recovered (SEIR) model. Using the SEIR model as their methodological anchor, authors estimated the COVID-19 epidemic parameters based on the data of reported infected cases and deaths in different parts of the world to predict the future epidemics of COVID-19 under different reopening policies (Chang et al. 2020; Liu et al. 2020; $\mathrm{Yu}$ et al. 2021). This section takes an alternative route to assess the COVID-19 exit strategy designed to gradually lift interventions introduced to control the outbreak in the State of São Paulo. We use our timely trade-based regional economic activity indicator (EAI) to circumvent the need for high-frequency regional economic information.

São Paulo is the State that has been hit the hardest in Brazil, with over 552,318 confirmed cases and 23,236 deaths through August 1, 2020 (Table 4). ${ }^{12}$ On March 29 , the State government issued an executive order closing all non-essential businesses to reduce the transmission of COVID-19. Sequentially, on May 29, a plan for gradually lifting restrictive measures on different economic sectors was crafted with representatives from the business community and public officials (health professionals, state-level secretaries, and mayors). To ensure the reopening would proceed smoothly and safely, decisions were to be driven by public health data. The São Paulo Plan defined a set of critical public health metrics, ${ }^{13}$ which would determine if, when, and where it would be appropriate to proceed through reopening phases. Public health data trends indicating significant increases in viral transmission could even return to prior phases or closing sectors of the economy. A dashboard monitored by the Contingency Centre allows permanent updates of public health indicators. Before and during reopening, these indicators must continue to show progress. As the regional economies reopen, the state administration provides guidance that each sector, industry, and business must follow. Finally, the Plan also includes a testing and tracing strategy that took off only recently.

The São Paulo Plan divided the economic opening of each DRS according to a phase classification ranging from 1 (more restrictive) to 5 (less restrictive). Figure 4 shows the timeline of phase change in each DRS of the State. Initially, all DRS were

\footnotetext{
12 The data about COVID-19-related deaths are reported in two different ways. Table 4 presents statistics of count of deaths according to date of register, whereas an alternative public source of information publishes deaths count by date of fatality.

${ }^{13}$ Five health indicators were grouped into two categories concerned with (i) health system capacity (average occupancy rate of ICU COVID beds in the last 7 days (\%), COVID ICU Beds / $100 \mathrm{k}$ habitants); and (ii) evolution of the pandemic (\# of new cases in the last 7 days / \# of new cases in the previous 7 days, \# of new hospitalizations in the last 7 days / \# of new hospitalizations in the previous 7 days, \# of deaths by COVID in the last 7 days / \# of deaths by COVID in the previous 7 days).
} 


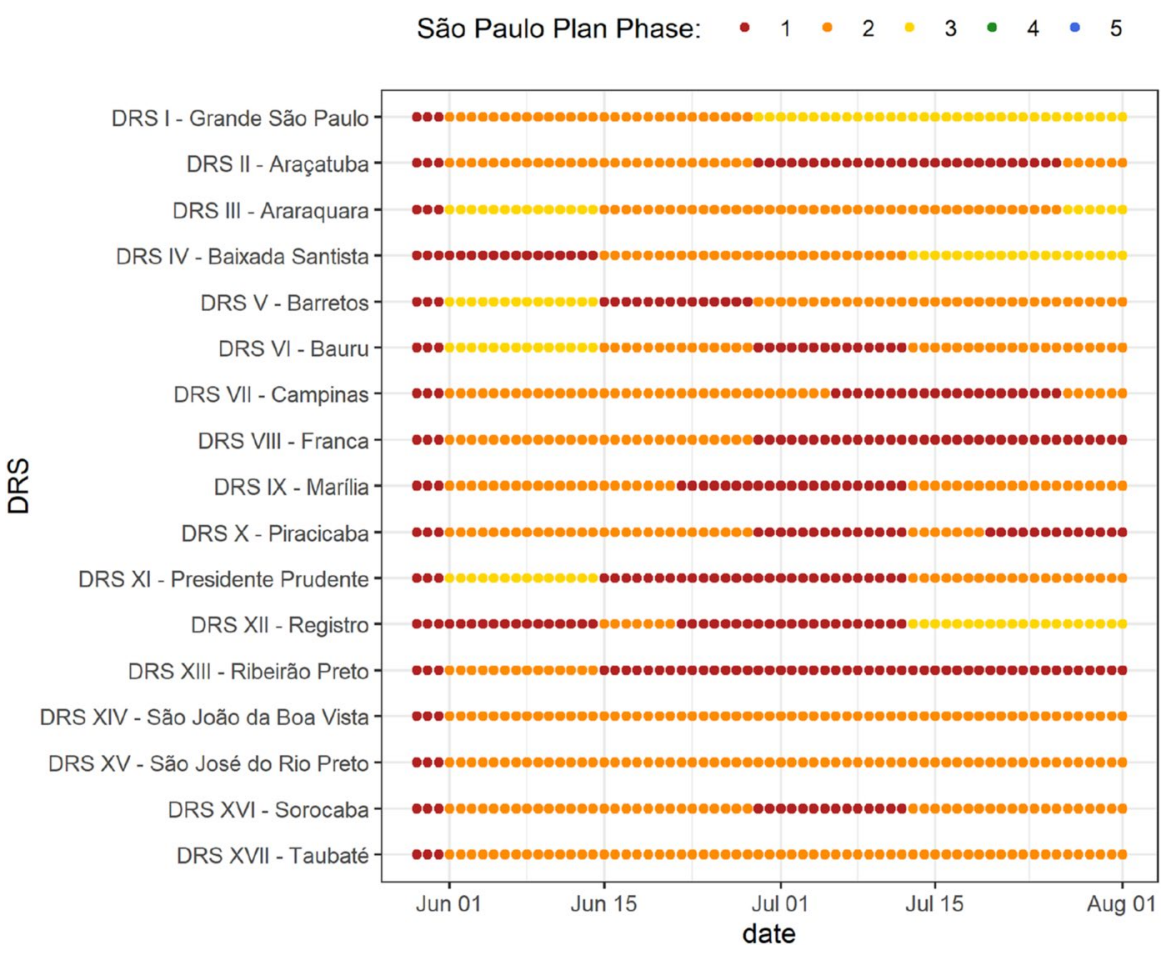

Fig. 4 Changes of Phases in Each DRS in the São Paulo Plan (May 29-August 1, 2020)

classified on phase 1. On June 1, the first phase changes were enacted, with 11 DRS being moved to phase 2 and 4 DRS to phase 3. Next, the phase of each DRS was changed up or down according to their health indicators. On August 1, 3 DRS were classified on phase 1, 10 DRS on phase 2, and 4 DRS on phase 3.

Therefore, the daily monitoring of health indicators in each DRS is critical for the sound implementation of the São Paulo Plan. However, the lack of timely, daily regional economic indicators precluded the broader monitoring of the Plan, as well as its proper evaluation. The use of the EAI provides a unique opportunity to close this gap. We can thus provide the first assessment of the Plan by combining the analysis of traffic, economic, and health indicators.

\subsection{Empirical strategy}

The objective of our empirical analyses is to provide an evaluation of the São Paulo Plan-in the first two months since its implementation-that considers both the effects of lifting interventions on the economic activity and the possible impact of easing restrictions on the spread of COVID-19. Specifically, we want to answer whether the changes of phases from the São Paulo Plan affected the COVID-19 spread through increased economic activity, measured by the proposed EAI. 
Table 5 Regression results: effect of phase change on EAI and mobility

\begin{tabular}{|c|c|c|c|c|}
\hline \multicolumn{3}{|l|}{ EAI } & \multicolumn{2}{|c|}{ Mobility index } \\
\hline $\begin{array}{l}\text { Tradable } \\
\text { (1) }\end{array}$ & $\begin{array}{l}\text { Non-tradable } \\
\text { (2) }\end{array}$ & $\begin{array}{l}\text { Total } \\
(3)\end{array}$ & $\begin{array}{l}\text { Freight } \\
\text { (4) }\end{array}$ & $\begin{array}{l}\text { Passengers } \\
\text { (5) }\end{array}$ \\
\hline $\begin{array}{l}0.412 * * * \\
(0.052)\end{array}$ & $\begin{array}{l}1.476 * * * \\
(0.115)\end{array}$ & $\begin{array}{l}1.110 * * * \\
(0.095)\end{array}$ & $\begin{array}{l}0.622 * * * \\
(0.187)\end{array}$ & $\begin{array}{l}2.212 * * * \\
(0.186)\end{array}$ \\
\hline $\begin{array}{l}0.718 * * * \\
(0.076)\end{array}$ & $\begin{array}{l}2.442 * * * \\
(0.168)\end{array}$ & $\begin{array}{l}2.322 * * * \\
(0.140)\end{array}$ & $\begin{array}{l}1.591 * * * \\
(0.275)\end{array}$ & $\begin{array}{l}3.666 * * * \\
(0.274)\end{array}$ \\
\hline
\end{tabular}

Fixed effects

\begin{tabular}{clllll} 
DRS & Yes & Yes & Yes & Yes & \multicolumn{1}{c}{ Yes } \\
Date & Yes & Yes & Yes & Yes & Yes \\
Obs & 1751 & 1751 & 1751 & 1751 & 1751 \\
$\mathrm{R}^{2}$ & 0.992 & 0.978 & 0.981 & 0.941 & 0.953 \\
\hline
\end{tabular}

$* p<0.1 ; * * p<0.01 ; * * * p<0.001$

Our empirical analysis will be separated into three steps:

1. Identify the effect of phase changes on the EAI.

2. Estimate the relationship between changes in the EAI and the spread of COVID19 in the State.

3. Compute a counterfactual exercise comparing the EAI and COVID-19 spread observed in the period of our analysis against what would happen if all DRS remained with the most restrictive classification for the economic activity.

The main challenge for estimating the effect of the São Paulo Plan on the epidemic is the endogeneity of variables. Changes in the phase classifications of DRS are not exogenous. Instead, they are decided based on the evolution of the disease in each region and the regions' health capacity to deal with it. Therefore, a simple estimation associating changes in classification and COVID-19 outcomes would likely lead to biased estimates of effects because regions with better health prospects are precisely the ones where economic restrictions are more likely to be removed. Given that, our empirical strategy tries to overcome this challenge by defining a structural path of causality. We first isolate the effect of phase changes on economic activity, assuming that parallel trends hold for this relation. Next, we assume that there is no reverse causality between COVID-19 outcomes and the EAI of regions.

\subsubsection{The effect of phase changes on the EAI}

For the first question, that is, the effect of phase changes on the economic activity, we estimate a fixed-effect model described by the following equation:

$$
E A I_{t, i}=\alpha_{i}+\tau_{d}+\beta_{2} F 2_{t, i}+\beta_{3} F 3_{t, i}+\varepsilon_{t, i}
$$


where $E A I_{t, i}$ is the economic activity index of region $i$ in date $t$. The fixed effects of the model are $\alpha_{i}$ that captures the region-specific means of the index, $\tau_{d}$ that controls for the evolution of the index regardless of phase changes. Including this latter set of controls is critical: it accounts for the fact that the economic activity was increasing in the different regions even without the official ease of economic restrictions. Finally, $F 2_{t, i}$ and $F 3_{t, i}$ are dummy variables that indicate if region $i$ is classified on either phase 2 or 3 on date $t$. Therefore, coefficients $\beta_{2}$ and $\beta_{3}$ represent the average marginal effect of regions classified on phases 2 and 3 of the São Paulo Plan.

Table 5 presents the results of this estimation. The dependent variable in columns 1-3 is the different EAI versions (tradables, non-tradables, and total). In columns 4 and 5 , the equation is estimated using internal regional mobility as the dependent variable instead of the EAI. ${ }^{14}$ The coefficients can be interpreted as the level effect of each phase compared to the level that would be expected if regions remained on phase 1. For example, the coefficient of 1.110 for phase 2 on total EAI indicates that moving from phase 1 to phase 2 leads to an average increase of 1.110 percentage points on total EAI. Results from all specifications are consistent, showing positive and significant effects of phase 2 and phase 3 in all indicators. While the effects for both phases are positive, they are larger for phase 3 , which is an expected result since the economic flexibility is higher in phases with higher classification. Moreover, the effects of moving to less restricted phases are stronger to non-tradable activities.

\subsubsection{The effect of EAI on COVID-19}

In the second step of our empirical analysis, we estimate the average effect of changes in the EAI on COVID-19 outcomes. Specifically, we estimate the following two specifications:

$$
\begin{gathered}
y_{t, i}=\left(\sum_{q} \gamma_{q} S_{q, t-7, i}\right)+\phi E A I_{t-t^{\prime}, i}+\epsilon_{t, i} \\
y_{t, i}=\left(\sum_{q} \gamma_{q} S_{q, t-7, i}\right)+\left(\sum_{q} \phi_{q} S_{q, t-t^{\prime}, i} E A I_{t-t^{\prime}, i}\right)+\epsilon_{t, i}
\end{gathered}
$$

where $y_{t, i}$ is a health variable measured in log per capita terms. Our preferred specification focuses our analysis on COVID-19-associated hospitalizations as this variable is less subject to measurement error and less likely to be under-notified if compared to COVID-19 cases or even deaths. ${ }^{15}$ Researchers are looking at the daily

\footnotetext{
${ }^{14}$ We measure intraregional mobility as the changes in values of traffic of passengers within each DRS, i.e., $\Delta F_{t, o, d}$, for $o=d$.

15 The number of deaths is usually a more consistent epidemiological statistic (Subaraman, 2020). However, our analysis evaluates a very recent period, and the number of deaths by date of occurrence tends to be underestimated in more recent dates because there is a substantial lag between death dates and their registration in official systems. Once COVID-associated death statistics are consolidated, an important robustness check will be to verify the consistency of our results using lagged COVID-19 deaths as the dependent variable of our model.
} 
Table 6 Regression results: effect of EAI changes on COVID-19 hospitalization rates
Log hospitalizations per million residents per day

(1)

(2)

\begin{tabular}{|c|c|c|}
\hline EAI (-12 days) average effect & $\begin{array}{l}0.005^{* * *} * \\
(0.002)\end{array}$ & \\
\hline \multicolumn{3}{|l|}{ Deaths per million (-12 days) } \\
\hline $0-100$ & & $\begin{array}{l}0.006 * * * \\
(0.002)\end{array}$ \\
\hline $100-200$ & & $\begin{array}{l}0.005 * * * \\
(0.002)\end{array}$ \\
\hline $200-300$ & & $\begin{array}{l}0.006 * * \\
(0.002)\end{array}$ \\
\hline $300-400$ & & $\begin{array}{l}0.004 * * \\
(0.002)\end{array}$ \\
\hline $400-500$ & & $\begin{array}{l}0.002 \\
(0.002)\end{array}$ \\
\hline $500-600$ & & $\begin{array}{l}0.020 \\
(0.002)\end{array}$ \\
\hline \multicolumn{3}{|l|}{ Fixed effects } \\
\hline $\begin{array}{l}\text { Accumulated deaths per } \\
\text { capita in }-7 \text { days }\end{array}$ & Yes & Yes \\
\hline Obs & 1.105 & 1.105 \\
\hline $\mathrm{R}^{2}$ & 0.406 & 0.410 \\
\hline
\end{tabular}

hospitalization rates attributed to COVID-19 to help guide the planning and prioritization of healthcare system resources (Garg et al. 2020). The first summation term on the right-hand side of both equations controls for the stage of the disease spread in each region over time. The term $S_{q, t, i}$ is a vector of dummies representing bins of the accumulated number of deaths in each DRS the week before each observation. ${ }^{16}$ This vector flexibly controls for the nonlinear pattern of the epidemiological evolution of the dependent variable. The main coefficient of interest is $\phi$ which estimates the marginal effect of lagged changes in the EAI on the dependent variable. The size of the lag term $t^{\prime}$ depends on the epidemiological characteristics of the dependent variable. Because we are focusing on COVID-19 hospitalizations, we use $t$ equal to 12 , representing the virus average estimated infection-to-death period of 24 days (Flaxman et al. 2020) minus the average period between mechanical ventilation and death that is observed in the State of São Paulo individual-level data of COVIDassociated deaths. The difference between the two specifications is associated with coefficient $\phi$. In Eq. 19, only a single average effect of lagged EAI is estimated.

\footnotetext{
${ }^{16}$ In our preferred specification, bins are defined as $0-100,100-200, \ldots, 700-800$ death per million residents.
} 


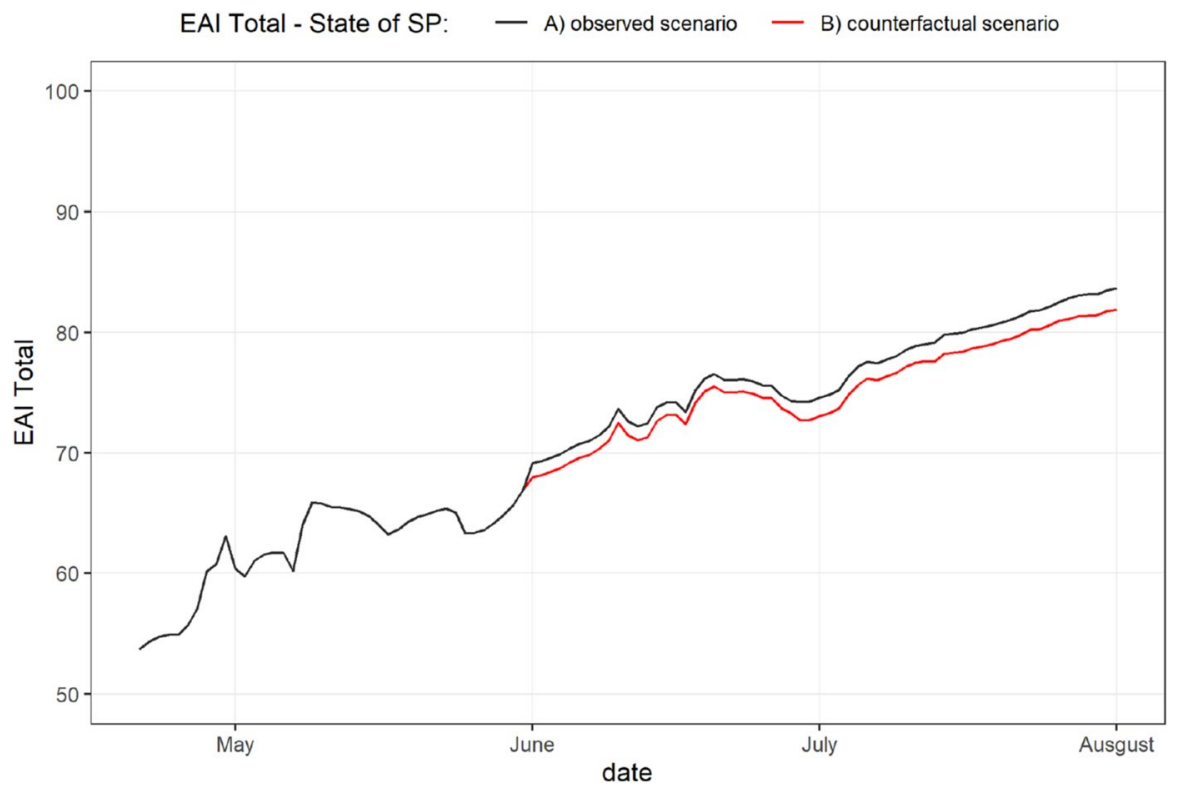

Fig. 5 Observed and Counterfactual EAI for the State of São Paulo

Meanwhile, Eq. 20 allows the EAI effect to varying according to the epidemic stage during the lagged period.

Table 6 presents the result of these estimations. Column (1) indicates that a one percentage point increase in EAI is, on average, associated with a $0.5 \%$ increase in the number of hospitalizations per capita after 12 days. Meanwhile, results from column (2) suggest that EAI effects are higher in the earlier stages of the pandemic. When deaths per million are below 100, a one percentage point is associated with a $0.6 \%$ increase in hospitalizations 12 days later. That effect decreases to $0.4 \%$ when COVID-19-associated deaths per million are between 300 and 400, and it becomes statistically non-significant above that level.

\subsubsection{Calculating the effect of the São Paulo Plan on COVID-19 hospitalizations}

The final step of our empirical framework combines the results of the previous two estimations to calculate the effect of the São Paulo Plan on COVID-19-associated hospitalizations in the period of our analysis. The calculation is based on a counterfactual analysis that uses the results of the previous two subsections to estimate total hospitalizations under two different scenarios: (A) the observed scenario and phase changes that the São Paulo Plan adopted; (B) an alternative scenario where all DRS remained under the most extreme economic restrictions (phase 1) throughout the whole period. By comparing the estimated number of hospitalizations in both scenarios, we estimate the impacts of the plan.

We start this procedure by calculating a counterfactual EAI for each region in scenario B $\left(\widehat{I A E}_{t, i}\right)$. This calculation can be described by Eq. 21 : 


$$
\widehat{E A I}_{t, i}=E A I_{t, i}-\hat{\beta}_{2} F 2_{t, i}-\hat{\beta}_{3} F 3_{t, i}
$$

The terms $\hat{\beta}_{2}$ and $\hat{\beta}_{3}$ are the results from Model (3) presented in Table 5 and correspond to the estimated effect phase changes on total EAI. Notice that if a region is already observed in phase 1 in scenario A, its EAI will be the same in both scenarios. Figure 5 shows the aggregated EAI for the State of São Paulo for both scenarios. The EAI is the same in both scenarios until the beginning of June, as all DRS were under the most restrictive classifications. With the beginning of changes in classifications in June, the difference between scenarios starts to show up, with slightly lower total EAI for the scenario where all regions are assumed to remain in phase 1. The difference between the scenarios increases over time as more regions are classified into more flexible phases. However, even on the last date of our comparison, the difference between the scenarios is only 1.93 percentage points.

Next, we use these simulated and observed EAI to project the number of hospitalizations in each DRS on each date using the results from Table 6. Specifically, we calculate:

$$
\begin{aligned}
& \hat{y}_{i, t}=\left(\sum_{q} \hat{\gamma}_{q, t-7, i} S_{q, t, i}\right)+\hat{\phi} E A I_{t-t^{\prime}, i} \\
& \hat{\hat{y}}_{i, t}=\left(\sum_{q} \hat{\gamma}_{q, t-7, i} S_{q, t, i}\right)+\hat{\phi} \widehat{E A I} \widehat{I t}_{t-t^{\prime}, i}
\end{aligned}
$$

That is, $\hat{y}_{i, t}$ corresponds to the fitted log of hospitalizations per capita in scenario $\mathrm{A}$, and $\hat{\hat{y}}_{i, t}$ is the corresponding value from scenario B. We can use $\hat{y}_{i, t}$ to $\hat{y}_{i, t}$ to project the total number of hospitalizations in each scenario. We run this calculation twofold: first assuming a single average effect of lagged EAI on new hospitalizations as reported on Table 6, Column (1); next, we allow the effect of lagged EAI to vary according to the stage of the pandemic using the coefficients from Column (2). In the first case, the number of hospitalizations in the counterfactual scenario would be $0.52 \%$ lower than the projected number using observed EAI. This difference could range between 0.15 and $0.95 \%$, given a $95 \%$ confidence interval and the standard errors of all estimates involved in the simulations. The observed number of COVID-19 hospitalizations in the State of São Paulo between May 29 and August 1 was 119,461 . Therefore, if we apply our main central effect to this total, we would have approximately 621 fewer new hospitalizations if no flexibility were adopted throughout the period. In the second case, where we allow more flexibility to the effect of EAI on hospitalizations, results are consistent. The simulated total number of hospitalizations would be $0.21 \%$ lower if economic restrictions were not released. This effect ranges from $0.04 \%$ to $0.59 \%$, given a $95 \%$ confidence interval of all estimates. The central result corresponds to 250 fewer hospitalizations between May 29 and August 1. 


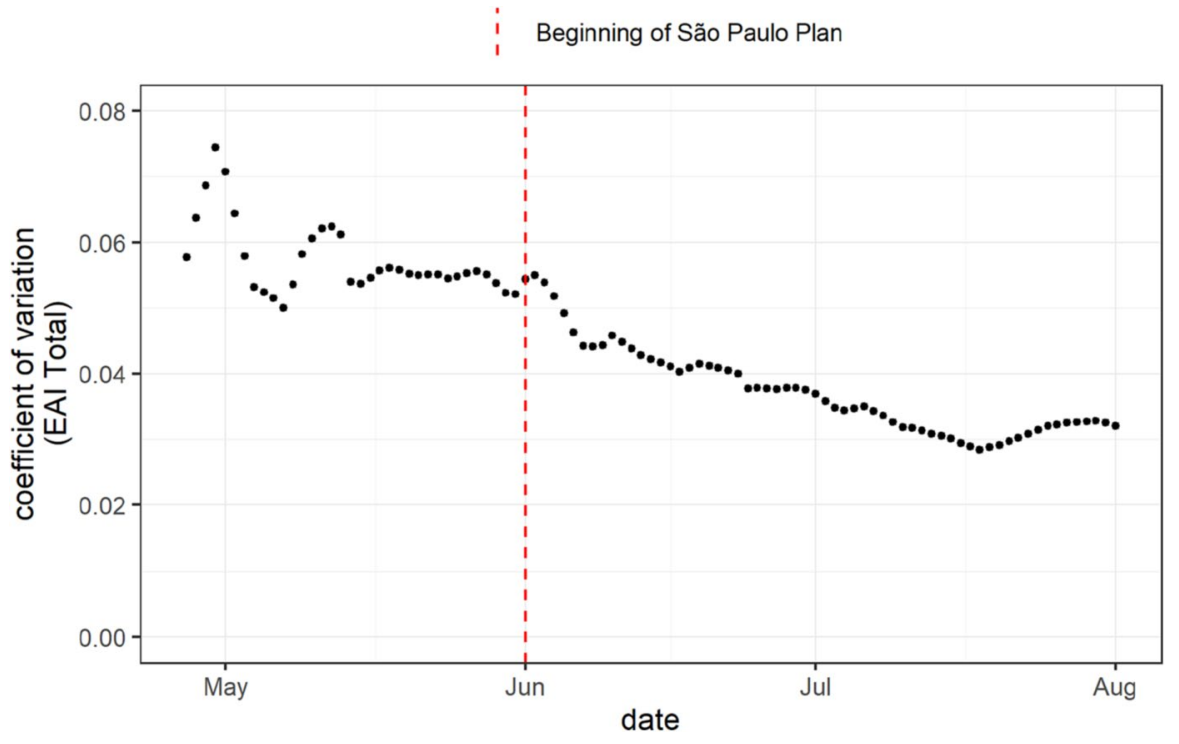

Fig. 6 Coefficient of Variation of Total EAI - (April, 21 - August 1, 2020)

\subsubsection{Calculating the effect of the São Paulo Plan on EAI volatility}

One additional objective of the São Paulo plan was to anchor expectations. ${ }^{17}$ It is a communication tool that allows economic agents to temporally allocate their efforts in production and consumption, reducing informational uncertainty due to the COVID-19 pandemic. To assess the effectiveness of the Sao Paulo Plan as a mechanism of anchoring expectations, we have estimated the daily coefficient of variation of the rolling-7-day EAI (Fig. 6 below). This descriptive analysis indicates that the São Paulo Plan may have smoothened the series and worked as an anchor for expectations guiding economic activity.

\section{Final discussion and possible extensions}

COVID-19 crisis monitoring involves preparing to implement and roll back nonpharmaceutical interventions, including setting up expert committees to examine initial control measures and defining gradual relaxing of social restrictions (Petersen et al. 2020). Nonetheless, up against enormous uncertainties, combining timely tracking of epidemiological and socioeconomic indicators is fundamental for informing officials during the implementation of exit strategies.

We proposed a timely trade-based regional economic activity indicator (EAI) combining high-frequency truck and passenger vehicle traffic data with economic

\footnotetext{
17 This follows the rational expectations argument frequently adopted in macroeconomic policy effectiveness discussions as explored by Lucas and Sargent (1981) and others.
} 
input-output flows. The EAI monitors daily sectoral economic activity in the Brazilian State of São Paulo. The use of this novel set of information, combined with COVID-19-associated hospitalizations, provided a first assessment of the São Paulo Plan, the COVID-19 exit strategy designed to gradually lifting interventions introduced to control the outbreak in the State. One of the contributions of this paper is to provide reliable estimates for the level of economic activity to evaluate the breakdown due to the COVID-19 in an environment of limited information from the economic and health side. Furthermore, since we implement short-run analysis (e.g., 60 first days), it is not necessary to consider if workers and people, in general, expected an improvement or worsening of the health conditions prevalent in the future in the regions and, thus, decreased their social exposure (affecting the economic activities).

In its first 60 days, we show that the phased strategy pursued in São Paulo has been effective in gradually reactivating economic activity pari passu to a relatively small number of additional hospitalizations associated with the flexibilization in phases. The timing of the reopening of non-essential activities has shown to be relevant to the impact on hospitalization rates increases, with more substantial effects during the ascending part of the pandemic curve. Thus, trends in the evolution of the pandemic should be part of the critical public health metrics monitored to determine smooth and safe reopening. Moreover, regional heterogeneity has proved to be an essential feature of the COVID-19 exit strategy. State coordination of preparedness efforts moving forward was an essential mechanism that considered the interconnectedness of the regional economies, which may be important at different spatial scales (Ruktanonchai et al. 2020). In Brazil, for instance, lack of national coordination in a strongly integrated interregional system may have contributed to complicating epidemiological assessments and public health efforts to curb the pandemic (Candido et al. 2020; Souza et al. 2020).

This study has significant limitations. The State of São Paulo is strongly connected with its neighboring states. According to the input-output data (FIPENEREUS 2020), interstate trade reaches almost fourfold international trade values involving the state economy. As the spread of diseases does not respect administrative borders (Ruktanonchai et al. 2020), the lack of coordinated nationwide measures to control the COVID-19 epidemic may have imposed limitations to the effectiveness of the São Paulo Plan.

Possible extensions of the EAI analysis include, but are not restricted to: (i) validation of the series' trend in comparison with invoice records to guarantee robustness in portraying economic activity; (ii) control of effect on disease spread by the expansion of testing; (iii) EAI sensitivity to local characteristics (for instance, the composition of regional economic structures, population socioeconomic characteristics); and (iv) EAI and labor market effects.

This study is the first of a series sought to facilitate crisis monitoring under an economic lens. Using literature on regional economic analysis and high-frequency traffic data, the model derives a connection between economic activity and health impacts. Given a straightforward means of anchoring expectations, we shed light on the possibility of inducing a responsible suspension of restrictive measures while keeping virus spread at bay. 
Supplementary Information The online version contains supplementary material available at https://doi. org/10.1007/s00168-021-01085-8.

Acknowledgements We are grateful for helpful comments from Alexandre Schwartsmann, Ana Carla Abrão, Pérsio Arida, and Santiago Falcão. We thank participants at the "Ciclo de Charlas Virtuales: El COVID-19 en América," Universidad Maimónides, Argentina; "COVID-19 Panel Challenges and Perspectives for Regional Economics," REAL, University of Illinois at Urbana-Champaign, USA; and the International Workshop "Current Trends in Regional/Urban Resilience and Sustainable Development," organized by the Bucharest University of Economic Studies team in collaboration with The Regional Science Academy.

Authors' contributions All authors contributed to the study. Conception and design were performed by Eduardo A. Haddad. Material preparation, data collection, and estimations were performed by Eduardo A. Haddad, Renato S. Vieira, Inácio F. Araújo, and Silvio Ichihara. Analysis was performed by Eduardo A. Haddad, Renato S. Vieira, Inácio F. Araújo, Fernando S. Perobelli, and Karina S. S. Bugarin. The first draft of the manuscript was written by Eduardo A. Haddad and all authors commented on previous versions of the manuscript. All authors read and approved the final manuscript.

Funding Eduardo A. Haddad acknowledges financial support from CNPq (Grant 302861/2018-1) and the National Institute of Science and Technology for Climate Change Phase 2 under CNPq Grant 465501/2014-1 and FAPESP Grant 2014/50848-9. Inácio F. Araújo acknowledges financial support from FAPESP Grant 2019/00057-9.

\section{Declarations}

Conflict of interest The authors declare that they have no conflict of interest.

Availability of data and materials The scripts and datasets analyzed in this study are available for replication at https://github.com/InacioAraujo/Replication-Materials.git

Code availability The scripts and datasets analyzed in this study are available for replication at https:// github.com/InacioAraujo/Replication-Materials.git

\section{References}

Ascani A, Faggian A, Montresor S (2021) The geography of COVID-19 and the structure of local economies: The case of Italy. J Reg Sci 61(2):407-441

Beenstock M, Felsenstein D, Zeev NB (2011) Capital deepening and regional inequality: an empirical analysis. Ann Reg Sci 47(3):599-617

Bennathan E, Fraser J and Thompson LS (1992) What determines demand for freight transport? WPS 998, Policy Research, The World Bank

Bonet J, Ricciulli-Marín D, Pérez-Valbuena GJ, Galvis-Aponte LA, Haddad EA, Araújo IF, Perobelli FS (2020) Regional economic impact of COVID-19 in Colombia: an input-output approach. Reg Sci Policy Pract 12(6):1123-1150

Boyce D, Willims H (2015) Forecasting urban travel: past, present and future. Edward Elgar, Cheltenham

Bourdin S, Jeanne L, Nadou F, Noiret G (2021) Does lockdown work? A spatial analysis of the spread and concentration of covid-19 in Italy. Reg Stud 55(7):1182-1193

Candido DS, Claro IM, De Jesus JG, Souza WM, Moreira FR, Dellicour S, Faria NR et al (2020) Evolution and epidemic spread of SARS-CoV-2 in Brazil. Science 369(6508):1255-1260

Capello R, Caragliu A (2021) Regional growth and disparities in a post-COVID Europe: a new normality scenario. J Reg Sci, pp 1-18

Chang S, Pierson E, Koh PW, Gerardin J, Redbird B, Grusky D, Leskovec J (2021) Mobility network models of COVID-19 explain inequities and inform reopening. Nature 589(7840):82-87 
Cole A (2005) Applied transport economics: policy, management and decision making. 3rd edition. Kogan Page, London

European Commission (2020) Coronavirus: Recommendation for the use of mobile data in response to the pandemic. https://ec.europa.eu/digital-single-market/en/news/coronavirus-recommendation-usemobile-data-response-pandemic. Accessed 17 Jul 2020

Flaxman S, Mishra S, Gandy A, Unwin H, Coupland H, Mellan T, Zhu H, Berah T, Eaton J and Guzman, P (2020) Report 13: Estimating the number of infections and the impact of non-pharmaceutical interventions on COVID-19 in 11 European countries. https://dsprdpub.cc.ic.ac.uk:8443/bitstream/ 10044/1/77731/10/2020-03-30-COVID19-Report-13.pdf. Accessed 17 Jul 2020

FIPE-NEREUS (2020) Fundação Instituto de Pesquisas Econômicas (FIPE). Núcleo de Economia Regional e Urbana da USP (NEREUS). Matriz Inter-regional de Insumo-Produto para os Departamentos Regionais de Saúde do Estado de São Paulo, 2015

Garg S, Kim L, Whitaker M (2020) Hospitalization rates and characteristics of patients hospitalized with laboratory-confirmed coronavirus disease 2019 - COVID-NET, 14 States, March 1-30. Morb Mortal Week Rep 69(15):458-464

Garcia C, Levy S, Limão S, Kupfer F (2008) Correlation between transport intensity and GDP in European Regions: a New Approach. In: 8th Swiss transport research conference, Monte Verità / Ascona, October 15-17, 2008

Global Health Platform (2020) Emerging COVID-19 success story: Germany's strong enabling environment, Oxford Martin School. https://ourworldindata.org/covid-exemplar-germany. Accessed 17 Jul 2020

Haddad EA, Bugarin K (2020) Crisis Control: The Use of Simulations for Policy Decisionmaking. Policy Brief, PB 20 - 38. Policy Center for the New South

Haddad EA, Mengoub FE, Vale VA (2020) Water content in trade: a regional analysis for morocco. Econ Syst Res 32(4):565-584. https://doi.org/10.1080/09535314.2020.1756228

Haddad EA, Perobelli FS, Araújo IF, Bugarin KS (2021) Structural propagation of pandemic shocks: an input-output analysis of the economic costs of COVID-19. Spat Econ Anal 16(3):252-270

Hamidi S, Ewing R, Sabouri S (2020) Longitudinal analyses of the relationship between development density and the COVID-19 morbidity and mortality rates: early evidence from 1165 metropolitan counties in the United States. Health Place 64:102378

Henderson JV (1986) Efficiency of resource usage and city size. J Urban Econ 19(1):47-70

Hooijmaaijers SHNA (2017) Is it possible for traffic intensity to become an economic indicator - research on Dutch international trade. Master Thesis, Tilburg University

Lahiri K, Yao W (2011) Should Transportation Output be Included as Part of the Coincident Indicators System? CESifo Working Paper No. 3477, www.cesifo.org/wp

Lahiri K, Stekler H, Yao W, Young P (2002) Monthly output index for the U.S. transportation sector. https://doi.org/10.2139/ssrn.345580

Li B, Gao S, Liang Y, Kang Y, Prestby T, Gao Y, Xiao R (2020) Estimation of regional economic development indicator from transportation network analytics. Sci Rep 10(1):1-15. https://doi.org/10. 1038/s41598-020-59505-2

Liu M, Thomadsen R, Yao S (2020) Forecasting the spread of COVID-19 under different reopening strategies. Sci Rep 10(1):1-8

Los B, Timmer MP, de Vries GJ (2016) Tracing value-added and double counting in gross exports: comment. Am Econ Rev 106(7):1958-1966. https://doi.org/10.1257/aer.20140883

Lucas RE, Sargent TJ (Eds) (1981) Rational expectations and econometric practice, v. 2, University of Minnesota Press

Mun SI, Hutchinson BG (1995) Empirical analysis of office rent and agglomeration economies: a case study of Toronto. J Reg Sci 35(3):437-456

National Research Council (2002) Key transportation indicators: summary of a workshop. The National Academies Press, Washington https://doi.org/10.17226/10404

Nolan L (2019) Faster indicators of U.K. economic activity. Data Science Campus, October 24, 2019. https://datasciencecampus.ons.gov.uk/faster-indicators-of-uk-economic-activity/

OECD (2020) Organization for Economic Co-operation and Development. Policy Responses to Coronavirus (COVID-19): COVID-19 crisis response in Central Asia 2000. https://www.oecd.org/coron avirus/policy-responses/covid-19-crisis-response-in-central-asia-5305f172/. Accessed 17 Jul 2020

Ortúzar JD, Willumsen LG (2011) Modelling transport, 4th edn. Wiley, New Jersey 
Petersen E, Wasserman S, Lee S-S, Go U, Holmes AH, Al-Abri S, McLellan S, Blumberg L, Tambyah P (2020) COVID-19 - We urgently need to start developing an exit strategy. Int J Infect Dis 96:233239. https://doi.org/10.1016/j.ijid.2020.04.035

Rodríguez-Pose A, Burlina C (2021) Institutions and the Uneven Geography of the First Wave of the COVID-19 Pandemic. J Reg Sci, pp 1-25

Ruktanonchai NW, Floyd JR, Lai S, Ruktanonchai CW, Sadilek A, Rente-Lourenco P, Prosper O (2020) Assessing the impact of coordinated COVID-19 exit strategies across Europe. Science 369(6510):1465-1470. https://doi.org/10.1126/science.abc5096

Sonis M, Hewings GJD, Guo J (1996) Sources of structural change in input-output systems: a field of influence approach. Econ Syst Res 8(1):15-32. https://doi.org/10.1080/09535319600000002

Souza WM, Buss LF, da Silva Candido D, Carrera JP, Li S, Zarebski AE, Faria NR et al (2020) Epidemiological and clinical characteristics of the COVID-19 epidemic in Brazil. Nat Hum Behav 4(8):856-865

Subbaraman N (2020) Why daily death tolls have become unusually important in understanding the coronavirus pandemic. Nature. https://doi.org/10.1038/d41586-020-01008-1

van Ruth F (2014) Traffic intensity as indicator of regional economic activity. Discussion paper 2014/21, Statistics Netherlands

World Health Organization (2020) Strengthening the health system response to COVID-19. https://www. euro.who.int/en/health-topics/health-emergencies/coronavirus-covid-19/technical-guidance/stren gthening-the-health-system-response-to-covid-19. Accessed 17 Jul 2020

Yu D, Zhu G, Wang X, Zhang C, Soltanalizadeh B, Wang X, Wu H (2021) Assessing effects of reopening policies on COVID-19 pandemic in Texas with a data-driven transmission model. Infect Dis Modell $6: 461-473$

Publisher's Note Springer Nature remains neutral with regard to jurisdictional claims in published maps and institutional affiliations.

\section{Authors and Affiliations}

\section{Eduardo A. Haddad ${ }^{1,2}$ (D) Renato S. Vieira ${ }^{3}$ (D) Inácio F. Araújo ${ }^{1}$ (D) Silvio M. Ichihara ${ }^{4} \cdot$ Fernando S. Perobelli $^{5} \mathbb{D} \cdot$ Karina S. S. Bugarin $^{6}$}

Renato S. Vieira

renato@rsvieira.com

Inácio F. Araújo

inacio.araujo@usp.br

Silvio M. Ichihara

Silvio.Ichihara@dersa.sp.gov.br

Fernando S. Perobelli

fernandosalgueiro.perobelli@gmail.com

Karina S. S. Bugarin

kssbugarin@gmail.com

1 Department of Economics, University of São Paulo, São Paulo, Brazil

2 Faculté de Gouvernance, Sciences Économiques et Sociales, Université Mohammed VI

Polytechnique, Ben Guerir, Morocco

3 Department of Economics, Universidade Católica de Brasília, Brasília, Brazil

4 DERSA, Secretariat of Logistics and Transportation, São Paulo, Brazil

5 Department of Economics, Federal University of Juiz de Fora, Juiz de Fora, Brazil

6 Economics and Politics Research Group, Brasília, Brazil 